Jurnal Ilmu Ilmu Agribisnis: Journal of Agribusiness Science, 9(2), Mei 2021

\title{
ANALISIS KINERJA PRODUKSI DAN STRATEGI PEMASARAN AGROINDUSTRI KERUPUK KEMPLANG DI KOTA BANDAR LAMPUNG
}

\author{
(Analysis of Production Performance and Marketing Strategy of Kerupuk Kemplang Agroindustry \\ in Bandar Lampung)
}

Andy Lareza, Adia Nugraha, Muhammad Irfan Affandi

Jurusan Agribisnis, Fakultas Pertanian, Universitas Lampung, Jl.Prof.Dr.Soemantri Brojonegoro No. 1, Bandar Lampung, 35145,e-mail: adia.nugraha@fp.unila.ac.id

\begin{abstract}
The purposes of this study are analyzing the production performance, identifying internal and external environment, and determining the priority of kerupuk kemplang agroindustry marketing strategy. The location of the study is determined deliberately as the consideration the area is the production center of kerupuk kemplang agroindustry in Bandar Lampung. The number of respondents are 14 kerupuk kemplang agroindustry owners that are randomly selected disproportionately. Data were collected in January February 2020. The analytical methods used are the analysis of production performance, SWOT (Strenghts, Weakness, Opportunities, Threats) analysis, and QSPM (Quantitative Strategic Planning Matrix) analysis. The results of the study indicated that kerupuk kemplang agroindustrial performance based on productivity aspect, capacity, quality, and speed of delivery are in good category, while based on the flexible aspects are not in good category. The main strength of kerupuk kemplang agroindustry is the location of strategic business and close to suppliers. Main drawback is the location of the business away from some consumers. The main opportunities are the need and high consumer interest on the product. The main threat is the supply of reduced raw material when approaching holiday seasons. The strategy of priority is improving the quality of products, following the bazaar organized by the government, utilizing technologies such as ecommerce and social media, collaborating with a kerupuk kemplang agent, and optimizing the utilization of strategic business locations to increase production volumes by improving cooperation with suppliers.
\end{abstract}

Key words: kerupuk kemplang agroindustry, marketing strategies, production performance

\section{PENDAHULUAN}

Sektor industri merupakan salah satu sektor yang berperan penting dalam pembangunan nasional. Sektor industri terhadap pembangunan nasional dari tahun ke tahun menunjukkan kontribusi yang signifikan terutama pada negara-negara berkembang. Keunggulan sektor industri tersebut diantaranya memberikan kontribusi bagi penyerapan tenaga kerja dan mampu menciptakan nilai tambah yang lebih tinggi pada berbagai komoditas yang dihasilkan. Kontribusi yang semakin tinggi dari sektor industri menyebabkan perubahan struktur perekonomian negara yang bersangkutan secara perlahan ataupun cepat dari sektor pertanian ke sektor industri (Saragih 2010).

Sektor industri diyakini sebagai sektor yang dapat memimpin sektor-sektor lain untuk kemajuan perekonomian. Industri terdiri dari industri menengah, industri kecil, dan industri rumah tangga. Industri kecil dan industri rumah tangga di Kota Bandar Lampung mengalami pertumbuhan yang baik setiap tahunnya.
Agroindustri merupakan salah satu bentuk industri hilir yang berbahan baku produk pertanian dan menekankan pada produk olahan dalam suatu perusahaan atau industri. Agroindustri memerlukan bahan baku untuk ditransformasikan dan menghasilkan suatu produk yang lebih bernilai. Supply bahan baku harus tetap dan berjalan agar agroindustri terus berproduksi (Saragih 2001).

Agroindustri kerupuk merupakan salah satu agroindustri yang ada di Kota Bandar Lampung. Industri rumah tangga pembuatan kerupuk yang terus berkembang dan sering dijumpai adalah kerupuk kemplang. Kerupuk kemplang dikenal sebagai makanan ringan khas daerah Sumatera bagian Selatan. Sentra agroindustri kerupuk kemplang di Kota Bandar Lampung berada di Sekip Rahayu Kecamatan Bumi Waras.

Agroindustri kerupuk kemplang di Kecamatan Bumi Waras masih mengalami keterbatasan alat dan mesin. Salah satu contoh keterbatasan alat dan mesin yang dialami agroindustri kerupuk kemplang adalah proses penjemuran kerupuk 
kemplang yang masih mengandalkan cahaya matahari. Ketika musim hujan, kerupuk kemplang tidak dapat dijemur. Jika kerupuk kemplang tidak dijemur, maka kerupuk kemplang tidak dapat mengembang ketika dipanggang, sehingga menjadi keras. Oven dapat menggantikan cahaya matahari untuk mengurangi kadar air dalam kerupuk kemplang, namun para pelaku agroindustri kerupuk kemplang di Kecamatan Bumi Waras tidak memiliki oven karena harga yang mahal. Hal tersebut tentunya dapat mengganggu proses produksi kerupuk kemplang. Apabila kinerja produksi agroindustri kurang baik, maka akan mengganggu kegiatan pemasaran.

Masalah lain yang dihadapi pelaku agroindustri kerupuk kemplang di Kecamatan Bumi Waras yaitu kemampuan dalam strategi pemasaran yang masih kurang baik. Menyusun strategi yang tepat haruslah melakukan analisis terhadap kondisi lingkungan internal dan lingkungan eksternal yang akan dihadapi, kemudian diambil alternatif untuk menentukan strategi yang harus dilakukan.

Agroindustri kerupuk kemplang dapat selalu memenuhi permintaan konsumen apabila kinerja produksinya baik. Kinerja produksi yang baik dengan didukung oleh strategi pemasaran yang baik akan meningkatkan penjualan produk dan keuntungan yang diperoleh agroindustri. Oleh karena itu, pelaku agroindustri perlu mengetahui kinerja agroindustri untuk mengevaluasi pencapaian agroindustri dan pelaku agroindustri perlu mengetahui faktor internal dan faktor eksternal yang mempengaruhi pemasaran produk agar dapat menentukan strategi pemasaran yang baik. Berdasarkan permasalahan tersebut, maka penelitian ini bertujuan untuk menganalisis kinerja produksi, mengidentifikasi lingkungan internal dan eksternal, serta menentukan prioritas strategi pemasaran kerupuk kemplang pada agroindustri kerupuk kemplang.

\section{METODE PENELITIAN}

Metode yang digunakan pada penelitian ini adalah metode studi kasus. Penelitian dilakukan di agroindustri kerupuk kemplang yang berada di Kecamatan Bumi Waras Kota Bandar Lampung. Penentuan lokasi penelitian dilakukan secara sengaja (purposive) dengan pertimbangan daerah tersebut merupakan sentra produksi kerupuk kemplang di Kota Bandar Lampung.

Responden kinerja produksi yaitu 14 produsen kerupuk kemplang yang berada di Kecamatan
Bumi Waras yang diambil secara acak tak proporsional. Responden strategi pemasaran sebanyak lima orang yang terdiri dari dua produsen kerupuk kemplang di Kecamatan Bumi Waras dengan pertimbangan produsen merupakan pemilik dengan kapasitas produksi tertinggi, satu orang konsumen yang ada di lokasi penelitian saat penelitian berlangsung, satu orang perwakilan Dinas Perindustrian Kota Bandar Lampung, dan satu orang dosen dari Jurusan Agribisnis Fakultas Pertanian Universitas Lampung.

Metode analisis kuantitatif dan deskriptif kualitatif digunakan untuk menganalisis kinerja produksi agroindustri kerupuk kemplang. Analisis kinerja produksi dilakukan untuk melihat hasil kerja dari agroindustri kerupuk kemplang berdasarkan aspek produktivitas, kapasitas, kualitas, kecepatan pengiriman, dan fleksibel.

Produktivitas adalah suatu ukuran untuk mengonversi input dari proses transformasi ke dalam output. Produktivitas dapat diukur menggunakan rumus berikut:

Produktivitas $=\frac{\text { Output }(\mathrm{Kg})}{\text { Input }(\mathrm{HOK})}$

Kapasitas adalah suatu ukuran yang menyangkut kemampuan output dari suatu proses. Kapasitas dapat diukur menggunakan rumus berikut:

Kapasitas $=\frac{\text { Actual Output }(\mathrm{Kg})}{\text { Design Capacity }(\mathrm{Kg})}$

Metode analisis deskriptif kualitatif digunakan untuk mengidentifikasi lingkungan internal dan lingkungan eksternal agroindustri kerupuk kemplang. Faktor internal terdiri dari kekuatan dan kelemahan, sedangkan faktor eksternal terdiri dari peluang dan ancaman. Menurut Rangkuti (2006) faktor-faktor tersebut selanjutnya dievaluasi menggunakan matriks Internal Factor Evaluation (IFE) dan matriks Eksternal Factor Evaluation (EFE).

Komponen faktor internal dan eksternal pada penelitian ini memiliki kesamaan dengan penelitian Deli, Widjaya, dan Endaryanto (2018). Faktor internal menggunakan unsur bauran pemasaran 4P (Product, Price, Place, Promotion), sedangkan faktor eksternal menggunakan komponen pesaing, konsumen, teknologi, dan pemasok.

Matriks IE digunakan untuk mengetahui arahan strategi yang akan dilaksanakan pada suatu usaha. 
Pemetaan matriks IE menggunakan total skor matriks IFE dan EFE.. Hasil matriks IE dapat mengidentifikasikan sembilan sel strategi usaha, tetapi pada prinsipnya kesembilan sel tersebut bisa dikelompokkan menjadi tiga strategi utama, yaitu grow and build pada sel I, II atau IV, hold and maintain pada sel III, V, atau sel VII, dan harvest and devest pada sel VI, VIII, atau IX.

Faktor internal dan eksternal yang didapatkan dari identifikasi dimasukkan ke dalam maktriks SWOT (Strenght, Weakness, Opportunities, Threat). Matriks SWOT dapat menghasilkan empat sel kemungkinan alternatif strategi yaitu strategi kekuatan-peluang (S-O), strategi kelemahanpeluang (W-O), strategi kelemahan-ancaman (W$\mathrm{T})$, dan strategi kekuatan-ancaman (S-T).

Analisis desktiptif kualitatif digunakan untuk menentukan prioritas strategi pemasaran kerupuk kemplang pada agroindustri kerupuk kemplang. Strategi yang sudah terbentuk dari matriks SWOT selanjutnya disusun berdasarkan prioritas yang diimplementasikan dengan menggunakan Quantitative Strategy Planning Matrix (QSPM). Unsur-unsur yang terdapat pada QSPM adalah strategi-strategi alternatif, faktor-faktor kunci, bobot, $\mathrm{AS}=$ nilai daya tarik, TAS = total nilai daya tarik, dan jumlah total nilai daya tarik.

\section{HASIL DAN PEMBAHASAN}

\section{Keadaan Umum Responden}

Kelompok umur pelaku agroindustri kerupuk kemplang yang menjadi responden yaitu 35-41 tahun sebanyak 64,29 persen, 42-48 tahun sebanyak 14,29 persen, dan 49-55 tahun sebanyak 21,43 persen. Tingkat pendidikan responden yaitu SD sebanyak 28,57 persen, SMP sebanyak 42,86 persen, dan SMA sebanyak 28,57 persen. Pengalaman usaha yang dimiliki responden yaitu 1-10 tahun sebanyak 64,29 persen, 11-20 tahun sebanyak 28,57 persen, dan 21-30 tahun sebanyak 7,14 persen.

\section{Profil Agroindustri Kerupuk Kemplang}

Industri rumah tangga pembuatan kerupuk kemplang di Kampung Sekip Rahayu Kecamatan Bumi Waras sudah ada sejak tahun 80-an. Awal mula pembuatan kerupuk kemplang dilakukan oleh etnis Cina. Berdasarkan data Dinas Perindustrian Kota Bandar Lampung (2019), jumlah agroindustri kerupuk kemplang di Kecamatan Bumi Waras yaitu sebanyak 40 agroindustri. Letak Kampung
Sekip Rahayu dekat dengan pasar gudang lelang dan pasar kangkung. Hal tersebut menjadikan Kampung Sekip Rahayu menjadi tempat yang ideal untuk membuat usaha kerupuk kemplang.

\section{Kinerja Produksi}

\section{Produktivitas}

Berdasarkan Tabel 1, rata-rata produktivitas antara output terhadap tenaga kerja agroindustri kerupuk kemplang di Kecamatan Bumi Waras adalah sebesar $11 \mathrm{~kg} / \mathrm{HOK}$. Artinya setiap satu HOK mampu memproduksi kerupuk kemplang sebesar $11 \mathrm{~kg} /$ hari. Penelitian Sari, Zakaria, dan Affandi (2015) mendapatkan hasil perhitungan rata-rata produktivitas tenaga kerja sebesar 7,26 kg/HOK dan hasil tersebut dapat dikategorikan baik. Artinya produktivitas tenaga kerja agroindustri kerupuk kemplang di Kecamatan Bumi Waras sudah dapat dikatakan baik.

\section{Kapasitas}

Berdasarkan Tabel 2, rata-rata kapasitas agroindustri kerupuk kemplang di Kecamatan Bumi Waras adalah 81 persen. Hal ini berarti agroindustri kerupuk kemplang di Kecamatan Bumi Waras sudah memanfaatkan penggunaan alat dan tenaga kerja secara efektif dan efisien karena nilai kapasitas yang mendekati 100 persen. Penelitian Putri, Haryono, dan Nugraha (2019) mendapatkan hasil perhitungan rata-rata kapasitas sebesar 78 persen dan hasil tersebut dapat dikategorikan baik. Artinya kapasitas produksi agroindustri kerupuk kemplang di Kecamatan Bumi Waras sudah dapat dikatakan baik.

Tabel 1. Produktivitas tenaga kerja pada agroindustri kerupuk kemplang di Kecamatan Bumi Waras

\begin{tabular}{lccc}
\hline \multicolumn{1}{c}{ Agroindustri } & $\begin{array}{c}\text { Output } \\
(\mathrm{Kg})\end{array}$ & HOK & $\begin{array}{c}\text { Produktivitas } \\
(\mathrm{Kg} / \mathrm{HOK})\end{array}$ \\
\hline Tiga Saudara & 100 & 8 & 13 \\
Ridho & 100 & 5 & 19 \\
Kemplang 131 & 75 & 8 & 10 \\
Dua Putri & 100 & 4 & 23 \\
Dinda & 50 & 4 & 11 \\
Azi & 25 & 4 & 7 \\
Kemplang 32 & 100 & 8 & 13 \\
Adit & 50 & 4 & 11 \\
Kemplang 23 & 50 & 9 & 6 \\
Yohana & 25 & 6 & 4 \\
Cinta & 50 & 8 & 6 \\
Agung & 50 & 5 & 10 \\
Thiara & 50 & 8 & 6 \\
Mickey Mouse & 50 & 5 & 10 \\
\hline Rata-rata & 62,50 & 6 & 11 \\
\hline
\end{tabular}


Tabel 2. Kapasitas produksi agroindustri kerupuk kemplang di Kecamatan Bumi Waras

\begin{tabular}{lccc}
\hline Agroindustri & $\begin{array}{c}\text { Output } \\
(\mathrm{Kg})\end{array}$ & $\begin{array}{c}\text { Output } \\
\text { Maksimal }(\mathrm{Kg})\end{array}$ & $\begin{array}{c}\text { Kapasitas } \\
\text { (persen) }\end{array}$ \\
\hline Tiga Saudara & 100 & 110 & 91 \\
Ridho & 100 & 100 & 100 \\
Kemplang 131 & 75 & 75 & 100 \\
Dua Putri & 100 & 100 & 100 \\
Dinda & 50 & 50 & 100 \\
Azi & 25 & 50 & 50 \\
Kemplang 32 & 100 & 100 & 100 \\
Adit & 50 & 100 & 50 \\
Kemplang 23 & 50 & 100 & 50 \\
Yohana & 25 & 50 & 50 \\
Cinta & 50 & 50 & 100 \\
Agung & 50 & 50 & 100 \\
Thiara & 50 & 100 & 50 \\
Mickey Mouse & 50 & 50 & 100 \\
\hline Rata-rata & 62,50 & 77,50 & 81 \\
\hline
\end{tabular}

\section{Kualitas}

Produk pada agroindustri kerupuk kemplang di Kecamatan Bumi Waras belum pernah diuji kandungan kimia dan cemaran mikroba, sehingga untuk mengukur kualitas kerupuk kemplang menggunakan parameter uji sensori. Spesifikasi parameter uji sensori kerupuk ikan pada SNI 8272:2016 yang diterbitkan oleh Badan Standardisasi Nasional (2016) yaitu kerupuk ikan berkualitas baik bila kenampakan utuh, rapih, bersih, ketebalan rata, warna cerah, bau khas ikan, rasa khas, tekstur sangat kering dan getas, dan tidak ada jamur. Kerupuk kemplang yang dihasilkan oleh agroindustri kerupuk kemplang di Kecamatan Bumi Waras aman untuk dikonsumsi karena tidak menggunakan bahan pengawet dan memenuhi syarat parameter uji sensori pada SNI 8272:2016 sehingga dapat dikatakan berkualitas baik.

\section{Kecepatan Pengiriman}

Kecepatan pengiriman diukur berdasarkan dua ukuran dimensi. Dimensi pertama dikatakan baik apabila proses pengiriman kerupuk kemplang oleh agroindustri dapat menempuh jarak $5 \mathrm{~km}$ dalam waktu 30 menit. Dimensi kedua dikatakan baik apabila agroindustri mengirimkan produk minimal satu kali dalam seminggu. Berdasarkan Tabel 3, rata-rata jarak tempuh per 30 menit adalah 15,78 $\mathrm{km}$ dan frekuensi pengiriman kerupuk kemplang adalah tiga kali per minggu. Artinya aspek kecepatan pengiriman pada agroindustri kerupuk kemplang di Kecamatan Bumi Waras sudah baik.

\section{Fleksibel}

Fleksibel bahan baku diukur melalui tiga tahapan. Tahapan pertama dikatakan baik apabila waktu dari datangnya bahan baku dan diproses menjadi kerupuk kemplang berkisar selama 2-3 hari. Tahapan kedua dikatakan baik jika dengan $50 \mathrm{~kg}$ tepung tapioka dan $5 \mathrm{~kg}$ ikan dapat menghasilkan $\geq 6000$ keping kerupuk kemplang. Tahapan ketiga adalah kemampuan agroindustri dalam mengubah tepung tapioka dan ikan menjadi produk selain kerupuk kemplang. Aspek fleksibel pada agroindustri kerupuk kemplang di Kecamatan Bumi Waras belum dapat dikatakan baik karena pada tahapan pengukuran ketiga belum dapat dilakukan.

Tabel 3. Kecepatan pengiriman agroindustri kerupuk kemplang di Kecamatan Bumi Waras

\begin{tabular}{lcccc}
\hline \multirow{2}{*}{ Agroindustri } & \multicolumn{3}{c}{ Dimensi 1 } & Dimensi 2 \\
\cline { 2 - 5 } & $\begin{array}{c}\text { Waktu } \\
(\text { menit })\end{array}$ & $\begin{array}{c}\text { Jarak Tempuh } \\
(\mathrm{km})\end{array}$ & $\begin{array}{c}\text { Jarak Tempuh per } \\
30 \text { menit }(\mathrm{km})\end{array}$ & $\begin{array}{c}\text { Frekuensi Pengiriman } \\
\text { per Minggu }\end{array}$ \\
\hline Tiga Saudara & 25 & 15 & 18,00 & 3 \\
Ridho & 5 & 1 & 6,00 & 3 \\
Kemplang 131 & 30 & 18 & 18,00 & 3 \\
Dua Putri & 10 & 7 & 21,00 & 3 \\
Dinda & 25 & 16 & 19,20 & 3 \\
Azi & 21 & 11 & 15,71 & 3 \\
Kemplang 32 & 25 & 15 & 18,00 & 3 \\
Adit & 10 & 7 & 21,00 & 3 \\
Kemplang 23 & 25 & 15 & 18,00 & 3 \\
Yohana & 5 & 1 & 6,00 & 3 \\
Cinta & 25 & 15 & 18,00 & 3 \\
Agung & 8 & 4 & 15,00 & 3 \\
Thiara & 10 & 7 & 21,00 & 3 \\
Mickey Mouse & 5 & 1 & 6,00 & 3 \\
\hline Rata-rata & 16,4 & 9,5 & 15,78 & 3 \\
\hline
\end{tabular}


Tabel 4. Fleksibel bahan baku pada agroindustri kerupuk kemplang di Kecamatan Bumi Waras

\begin{tabular}{lccc}
\hline Agroindustri & $\begin{array}{c}\text { Jumlah Waktu Produksi } \\
\text { Kerupuk Kemplang } \\
\text { (hari) }\end{array}$ & $\begin{array}{c}\text { Produksi Kerupuk Kemplang dari 50 } \\
\text { kg Tepung Tapioka dan 5 kg Ikan } \\
\text { (keping) }\end{array}$ & $\begin{array}{c}\text { Produk Olahan } \\
\text { Lain Dari Tepung } \\
\text { Tapioka dan Ikan }\end{array}$ \\
\hline Tiga Saudara & $2-3$ & 6.000 & Tidak Ada \\
Ridho & $2-3$ & 6.000 & Tidak Ada \\
Kemplang 131 & $2-3$ & 6.000 & Tidak Ada \\
Dua Putri & $2-3$ & 6.000 & Tidak Ada \\
Dinda & $2-3$ & 6.000 & Tidak Ada \\
Azi & $2-3$ & 6.000 & Tidak Ada \\
Kemplang 32 & $2-3$ & 6.000 & Tidak Ada \\
Adit & $2-3$ & 6.000 & Tidak Ada \\
Kemplang 23 & $2-3$ & 6.000 & Tidak Ada \\
Yohana & $2-3$ & 6.000 & Tidak Ada \\
Cinta & $2-3$ & 6.000 & Tidak Ada \\
Agung & $2-3$ & 6.000 & Tidak Ada \\
Thiara & $2-3$ & 6.000 & Tidak Ada \\
Mickey Mouse & $2-3$ & 6.000 & Tidak Ada \\
\hline
\end{tabular}

\section{Penerapan Strategi Pemasaran}

\section{Kondisi Lingkungan Internal}

a. Produk

Kerupuk kemplang yang dihasilkan agroindustri di Kecamatan Bumi Waras memiliki kualitas yang baik karena bahan baku yang digunakan berkualitas baik. Bahan baku kerupuk kemplang yaitu tepung tapioka dan ikan. Pelaku agroindustri kerupuk kemplang menggunakan tepung tapioka Cap Jangkar Mas Berlian yang sudah terdapat izin Badan Pengawas Obat dan Makanan (BPOM), artinya keamanan dan kualitasnya sudah teruji. Ikan yang digunakan adalah ikan jolot. Ikan jolot memiliki rasa yang mirip dengan ikan belida dan ikan tenggiri, namun ikan jolot memiliki harga yang lebih ekonomis.

b. Harga

Penetapan harga kerupuk kemplang yang dilakukan oleh pelaku agroindustri kerupuk kemplang di Kecamatan Bumi Waras sudah memperhitungkan semua biaya yang dikeluarkan untuk memproduksi kerupuk kemplang. Sebagian besar agroindustri kerupuk kemplang hanya memiliki satu jenis ukuran dan satu jenis harga.

c. Promosi

Pelaku agroindustri kerupuk kemplang di Kecamatan Bumi Waras telah melakukan promosi di sekitar lokasi usaha dan pasar dengan personal selling. Personal selling adalah promosi dengan cara berkomunikasi langsung dengan pelanggan potensial. Pelaku agroindustri kerupuk kemplang melakukan promosi dengan cara menawarkan produk ke toko oleh-oleh dan toko makanan di pasar sekitar lokasi usaha. Promosi dengan cara Personal selling sudah memberikan dampak yang baik bagi agroindustri yaitu menghasilkan kerjasama jangka panjang antara agroindustri kerupuk kemplang dengan pemilik toko.

d. Tempat

Lokasi agroindustri kerupuk kemplang di Kecamatan Bumi Waras dekat dengan pasar kangkung dan pasar gudang lelang. Pelaku agroindustri kerupuk kemplang mendapatkan pasokan bahan baku dari pasar kangkung dan pasar gudang lelang. Lokasi usaha yang dekat dengan pemasok memberikan keuntungan untuk agroindustri yaitu meminimalisir biaya transportasi dan kemungkinan terjadinya kerusakan bahan baku kecil. Lokasi usaha yang dekat dengan pasar juga memudahkan pemasaran kerupuk kemplang.

2. Kondisi Lingkungan Eksternal

a. Pesaing

Pesaing dari usaha sejenis mempunyai manfaat yang positif bagi agroindustri, karena agroindustri akan termotivasi untuk meningkatkan mutu produk, menekan biaya produksi, dan melakukan inovasi dalam pengembangan produk. Agroindustri kerupuk kemplang di Kecamatan Bumi Waras berjumlah empat puluh, artinya terdapat banyak pesaing dari usaha sejenis.

b. Konsumen

Permintaan konsumen terhadap kerupuk kemplang termasuk tinggi, karena kerupuk 
kemplang sering dijadikan sebagai oleh-oleh dan camilan. Konsumen agroindustri kerupuk kemplang di Kecamatan Bumi Waras tidak hanya dari Kota Bandar Lampung. Beberapa agroindustri sudah bekerjasama dengan agen untuk menjual kerupuk kemplang ke luar kota seperti Pesawaran, Pringsewu, dan Lampung Timur.

c. Teknologi

Pelaku agroindustri kerupuk kemplang di Kecamatan Bumi Waras sudah memanfaatkan teknologi informasi dan komunikasi dengan cukup baik, seperti penggunaan handphone dan whatsapp sebagai alat komunikasi dengan pelanggan. Penggunaan teknologi dalam proses produksi kerupuk kemplang belum dapat dikatakan baik. Keterbatasan modal dan harga alat produksi moderen yang mahal membuat teknologi produksi pada agroindustri kerupuk kemplang di Kecamatan Bumi Waras belum berkembang.

d. Pemasok

Pelaku agroindustri kerupuk kemplang di Kecamatan Bumi Waras sudah memiliki pemasok masing-masing. Lokasi agroindustri kerupuk kemplang yang dekat dengan pasar memudahkan agroindustri dalam mendapatkan pemasok. Ketika mendekati hari raya, pemasok kekurangan persediaan bahan baku karena permintaan yang tinggi.

\section{Analisis SWOT}

\section{Faktor Internal}

Berdasarkan hasil perhitungan pada Tabel 5, dapat diketahui bahwa faktor kekuatan lokasi usaha strategis dan dekat pemasok mendapatkan ranking satu dengan skor 0,8000. Artinya lokasi usaha yang strategis dan dekat dengan pemasok berpengaruh sangat kuat dalam pemasaran kerupuk kemplang dibandingkan dengan faktor kekuatan lainnya.

Faktor kelemahan lokasi usaha jauh dari beberapa konsumen mendapatkan ranking satu dengan skor 0,3750 . Artinya lokasi usaha jauh dari beberapa konsumen adalah kelemahan yang paling berpengaruh dalam pemasaran kerupuk kemplang dibandingkan dengan faktor kelemahan lainnya. Hasil ini berbeda dengan penelitian Khairunnisa (2017) bahwa komponen harga adalah komponen yang paling berpengaruh dalam pemasaran emping melinjo di Provinsi Lampung.

\section{Faktor Eksternal}

Berdasarkan hasil perhitungan pada Tabel 6, dapat diketahui bahwa faktor peluang kebutuhan dan minat konsumen terhadap produk tinggi mendapatkan ranking satu dengan skor 0,5464. Artinya kebutuhan dan minat konsumen terhadap produk tinggi adalah yang paling berpengaruh dalam pemasaran kerupuk kemplang dibandingkan faktor peluang lainnya.

Faktor ancaman pasokan bahan baku berkurang ketika mendekati hari raya mendapatkan ranking satu dengan skor 0,4179. Artinya pasokan bahan baku yang berkurang ketika mendekati hari raya dapat menjadi ancaman yang paling berpengaruh terhadap terhambatnya pemasaran kerupuk kemplang dibandingkan faktor ancaman lainnya. Hasil ini serupa dengan penelitian Khairunnisa (2017) bahwa komponen pemasok merupakan komponen yang paling berpengaruh terhadap terhambatnya pemasaran emping melinjo di Provinsi Lampung.

Tabel 5. Matriks IFE (Internal Factor Evaluation) agroindustri kerupuk kemplang di Kecamatan Bumi Waras Kota Bandar Lampung

\begin{tabular}{|c|c|c|c|c|c|}
\hline No. & Faktor Internal & Bobot & Rating & Skor & Ranking \\
\hline 1. & Kekuatan & & & & \\
\hline a & Bahan baku dan produk berkualitas & 0,1607 & 3 & 0,4821 & 3 \\
\hline b & Harga sesuai dengan kualitas produk & 0,1929 & 4 & 0,7714 & 2 \\
\hline $\mathrm{c}$ & $\begin{array}{l}\text { Promosi telah dilakukan di sekitar lokasi dan pasar dengan } \\
\text { personal selling }\end{array}$ & 0,1357 & 3 & 0,4071 & 4 \\
\hline $\mathrm{d}$ & Lokasi usaha strategis dan dekat pemasok & 0,2000 & 4 & 0,8000 & 1 \\
\hline 2. & Kelemahan & & & & \\
\hline a & Produk mudah hancur & 0,0821 & 3 & 0,2464 & 2 \\
\hline b & Harga tidak bervariasi & 0,0143 & 3 & 0,0429 & 4 \\
\hline $\mathrm{c}$ & Belum terdapat PIRT & 0,0893 & 2 & 0,1786 & 3 \\
\hline \multirow[t]{2}{*}{$\mathrm{d}$} & Lokasi usaha jauh dari beberapa konsumen & 0,1250 & 3 & 0,3750 & 1 \\
\hline & Total & 1,0000 & & 3,3036 & \\
\hline
\end{tabular}


Tabel 6. Matriks EFE (External Factor Evaluation) agroindustri kerupuk kemplang di Kecamatan Bumi Waras Kota Bandar Lampung

\begin{tabular}{rlcccc}
\hline No. & \multicolumn{1}{c}{ Faktor Eksternal } & Bobot & Rating & Skor & Ranking \\
\hline 1. & Peluang & & & & \\
a & Daya saing produk tinggi & 0,1357 & 3 & 0,4071 & 3 \\
b & Kebutuhan dan minat konsumen terhadap produk tinggi & 0,1821 & 3 & 0,5464 & 1 \\
c & Pemanfaatan teknologi oleh agroindustri & 0,1393 & 2 & 0,2786 & 4 \\
d & Agroindustri sudah bermitra dengan beberapa pemasok & 0,1536 & 3 & 0,4607 & 2 \\
\hline 2. & Ancaman & & & & \\
a & Terdapat banyak pesaing dari usaha yang sejenis & 0,0571 & 4 & 0,2286 & 3 \\
b & Sebagian konsumen jauh dari lokasi usaha & 0,1357 & 3 & 0,4071 & 2 \\
c & Perkembangan teknologi yang sulit diikuti karena & 0,0571 & 2 & 0,1143 & 4 \\
& memerlukan biaya yang tinggi & & & \\
d & Pasokan bahan baku berkurang ketika mendekati hari raya & 0,1393 & 3 & 0,4179 & 1 \\
\hline & Total & 1,0000 & & 2,8607 & \\
\hline
\end{tabular}

\section{Matriks IE}

Berdasarkan hasil pemetaan total skor IFE dan EFE, agroindustri kerupuk kemplang di Kecamatan Bumi Waras berada di posisi sel 4. Strategi yang dapat diterapkan pada sel 4 adalah grow and build melalui penetrasi pasar, pengembangan pasar, dan pengembangan produk. Strategi penetrasi pasar yaitu agroindustri berfokus pada penjualan produk di pasar yang telah ada sebelumnya. Strategi pengembangan pasar yaitu agroindustri berusaha untuk menjual produk di pasar yang baru. Strategi pengembangan produk yaitu agroindustri memperkenalkan produk baru ke pasar yang telah ada sebelumnya. Hasil yang serupa terdapat pada penelitian Setyorini, Effendi, dan Santoso (2016) yaitu matriks IE Restoran WS Soekarno Hatta Malang berada di posisi sel 4 dan menerapkan strategi grow and build.

\section{Alternatif Strategi}

Alternatif strategi yang diperoleh berdasarkan analisis SWOT adalah:

a. Peningkatan kualitas produk agar unggul dalam persaingan antara produk sejenis.

b. Pemanfaatan teknologi seperti e-commerce dan sosial media sebagai alat promosi untuk memperluas pasar.

c. Optimalisasi pemanfaatan lokasi usaha yang strategis untuk meningkatkan volume produksi dengan cara meningkatkan kerjasama dengan pemasok.

d. Melakukan inovasi terhadap bentuk kerupuk kemplang agar dapat bersaing dengan usaha sejenis.

e. Mengurus PIRT untuk meningkatkan kepercayaan konsumen serta menambah area pemasaran produk seperti mini market. f. Mengikuti bazar yang diselenggarakan oleh pemerintah maupun swasta sebagai salah satu langkah mempromosikan produk agar lebih dikenal.

g. Peningkatan volume produksi sebelum memasuki bulan ramadhan, sehingga permintaan kerupuk kemplang yang tinggi ketika hari raya dapat terpenuhi tanpa ada masalah kekurangan bahan baku.

h. Melakukan inovasi pada kemasan kerupuk kemplang sehingga konsumen tertarik untuk membeli kerupuk kemplang.

i. Bekerjasama dengan agen kerupuk kemplang agar dapat memenuhi permintaan konsumen dari luar kota.

\section{Tahap Keputusan}

Strategi prioritas yang diperoleh berdasarkan analisis QSPM adalah:

1. Peningkatan kualitas produk

Pelaku agroindustri kerupuk kemplang dapat mengatasi persaingan antara produk sejenis dengan cara meningkatkan kualitas produk, contohnya meningkatkan persentase ikan dalam adonan kerupuk kemplang.

2. Mengikuti bazar yang diselenggarakan oleh pemerintah maupun swasta

Masyarakat yang hadir dalam bazar datang dari berbagai wilayah dan usia. Hal tersebut harus dimanfaatkan oleh pelaku agroindustri kerupuk kemplang sebagai salah satu langkah mempromosikan produk agar lebih dikenal.

3. Pemanfaatan teknologi seperti e-commerce dan sosial media

Pelaku agroindustri kerupuk kemplang dapat memanfaatkan e-commerce seperti bukalapak dan shopee serta sosial media seperti facebook dan instragram untuk memperluas pasar. 
4. Bekerjasama dengan agen kerupuk kemplang Bekerjasama dengan agen kerupuk kemplang adalah salah satu cara untuk mengatasi jarak antara konsumen dan podusen yang jauh, sehingga konsumen dapat membeli kerupuk kemplang dengan harga yang tidak berbeda jauh ketika membeli langsung di produsen.

5. Optimalisasi pemanfaatan lokasi usaha yang strategis

Lokasi agroindustri kerupuk kemplang di Kecamatan Bumi Waras dekat dengan pasar gudang lelang yang disebut juga pasar ikan. Ikan yang dijual di pasar tersebut terbilang segar dan harganya pun murah. Pelaku agroindustri kerupuk kemplang dapat memanfaatkan hal tersebut untuk meningkatkan volume produksi dengan cara meningkatkan kerjasama dengan pemasok.

Hasil penyusunan prioritas strategi pada penelitian ini memiliki beberapa persamaan dengan penelitian Kasymir, Haryono, dan Prayitno (2019) yaitu meningkatkan kualitas produk dan meningkatkan kerjasama dengan pemasok.

\section{KESIMPULAN}

Kinerja agroindustri kerupuk kemplang di Kecamatan Bumi Waras berdasarkan aspek produktivitas, kapasitas, kualitas, dan kecepatan pengiriman sudah baik, sedangkan berdasarkan aspek fleksibel belum dapat dikatakan baik. Kekuatan utama agroindustri kerupuk kemplang adalah lokasi usaha strategis dan dekat pemasok, kelemahan utama adalah lokasi usaha jauh dari beberapa konsumen, peluang utama adalah kebutuhan dan minat konsumen terhadap produk tinggi, ancaman utama adalah pasokan bahan baku berkurang ketika mendekati hari raya. Strategi pemasaran kerupuk kemplang yang menjadi prioritas yaitu peningkatan kualitas produk, mengikuti bazar yang diselenggarakan oleh pemerintah maupun swasta, pemanfaatan teknologi seperti e-commerce dan sosial media, bekerjasama dengan agen kerupuk kemplang, dan optimalisasi pemanfaatan lokasi usaha yang strategis.

\section{DAFTAR PUSTAKA}

Badan Standardisasi Nasional. 2016. Standar Nasional Indonesia 8272:2016, Kerupuk Ikan, Udang, dan Moluska. Badan Standardisasi Nasional. Jakarta.
Deli RO, Widjaya S, dan Endaryanto T. 2018. Analisis strategi pemasaran berbagai produk berbasis ikan bandeng di Provinsi Lampung. Jurnal Ilmu Ilmu Agribisnis, 6(2): 155-162. http://jurnal.fp.unila.ac.id/index.php/JIA/articl e/view/2781/2327. [16 Juli 2020].

Dinas Perindustrian Kota Bandar Lampung. 2019. Data Agroindustri Kerupuk Kemplang di Kecamatan Bumi Waras Kota Bandar Lampung Tahun 2019. Bandar Lampung.

Kasymir DA, Haryono D, dan Prayitno RT. 2019. Strategi pemasaran PT Sayuran Siap Saji Kabupaten Bogor Jawa Barat. Jurnal Ilmu Ilmu Agribisnis, 7(3): 306-313. http://jurnal.fp.unila.ac.id/index.php/ JIA/article/view/3767/2768. [16 Juli 2020].

Khairunnisa T. 2017. Analisis Efisiensi dan Strategi Pemasaran Emping Melinjo di Provinsi Lampung. Skripsi. Fakultas Pertanian Universitas Lampung. Bandar Lampung.

Putri RM, Haryono D, dan Nugraha A. 2019. Analisis kinerja dan lingkungan internal eksternal agroindusri keripik pisang (studi kasus di Desa Sungai Langka Kabupaten Pesawaran). Jurnal Ilmu Ilmu Agribisnis, 7(2): $\quad$ 203-210. http://jurnal.fp.unila.ac.id/index.php/JIA/articl e/view/3382/2583. [16 Juli 2020].

Rangkuti F. 2006. Analisis SWOT Teknik Membedah Kasus Bisnis. PT Gramedia Pustaka Utama. Jakarta.

Saragih B. 2001. Agribisnis Paradigma Baru Pembangunan Ekonomi Berbasis Pertanian, Kumpulan Pemikiran. PT Surveyor Indonesia dan Pusat Studi Pembangunan LP-IPB. Jakarta.

2010. Paradigma Baru Pembangunan Ekonomi Berbasis Pertanian. IPB Press. Bogor.

Sari IRM, Zakaria WA, dan Affandi MI. 2015. Kinerja produksi dan nilai tambah agroindustri emping melinjo di Kota Bandar Lampung. Jurnal Ilmu Ilmu Agribisnis, 3(1): 18-25.

http://jurnal.fp.unila.ac.id/index.php/JIA/articl e/view/1013/918. [18 Oktober 2019].

Setyorini H, Effendi M, dan Santoso I. 2016. Analisis strategi pemasaran menggunakan matriks SWOT dan QSPM (studi kasus: Restoran WS Soekarno Hatta Malang). Jurnal Teknologi dan Manajemen Agroindustri, 5(1): 46-53. https://industria.ub.ac.id/index.php/industri/art icle/view/269/261. [19 April 2020]. 